\title{
Clinical and Biochemical Manifestations of Severe Sickle Cell Anemia in Adult Patients in Steady State in Ile-Ife, Nigeria
}

Corresponding Author: Oguntoye Oluwatosin Oluwagbenga;

email: proflast@yahoo.com

Received 9 February 2019 Accepted 26 March 2019 Published 31 March 2019

Production and Hosting by Knowledge E

(c) Oguntoye Oluwatosin Oluwagbenga et al. This article is distributed under the terms of the Creative

Commons Attribution

which permits

unrestricted use and

redistribution provided that the original author and source are credited.

Editor-in-Chief:

Prof. Mohammad A. M. Ibnouf

\section{Oguntoye Oluwatosin Oluwagbenga ${ }^{1}$, Ndububa Dennis A. ${ }^{2}$, Yusuf Musah. ${ }^{1}$, Bolarinwa Rahman $A_{\circ}{ }^{3}$, and Ayoola Oluwagbemiga 0.4}

${ }^{1}$ Department of Internal Medicine, Afe Babalola University Ado-Ekiti/Federal Teaching Hospital, Ido-Ekiti, Ekiti State, Nigeria

${ }^{2}$ Department of Medicine, Obafemi Awolowo University, Ile-Ife/Obafemi Awolowo University Teaching Hospitals Complex, Ile-Ife, Osun State, Nigeria

${ }^{3}$ Department of Hematology, Obafemi Awolowo University, Ile-Ife/Obafemi Awolowo University Teaching Hospitals Complex, Ile-Ife, Osun State, Nigeria

${ }^{4}$ Department of Radiology, Obafemi Awolowo University, Ile-Ife/Obafemi Awolowo University Teaching Hospitals Complex, Ile-Ife, Osun State, Nigeria

\section{Abstract}

Background: There are documented established markers (indices) of disease severity in patients with sickle cell anemia (SCA) and they determine the course of the disease. This study investigated the pattern and prevalence of some of these markers of disease severity in adult patients with SCA in steady state attending the hematology clinic of a federal tertiary teaching hospital in Ile-Ife, Nigeria.

Materials and Methods: This was a descriptive study. Basic demographic data and relevant clinical information was obtained using a well-structured questionnaire and the case files (hospital records) of 50 consecutive SCA (HbSS) patients.

Results: The study group comprised of $21(42 \%)$ males and $29(58 \%)$ females. The age range was $18-45 y e a r s$ with a mean $( \pm S D)$ of $27.6 \pm 7.607$. Hepatomegaly $(64 \%)$, frequent episodes of vaso-occlusive crisis, that is, $\geq 3$ episodes per year(30\%) and Dactylitis in infanthood(26\%) were the most common clinical parameters identified in these patients while a high serum total bilirubin of $>51 \mu \mathrm{mol} / \mathrm{L}(26 \%)$ was the most common laboratory parameter seen in these patients.

Conclusion: Markers of disease severity were identified in the patients with SCA in this study. The presence of these markers in an SCA patient connotes severe disease and they determine the course of the disease. Therefore, there is a need to pay more attention to these patients by following them up more closely.

Keywords: disease severity, markers, sickle cell anemia, steady state, adults, patients 


\section{Introduction}

Sickle cell anemia (SCA) is an autosomal recessive genetic disorder caused by a defect in the HBB gene which codes for hemoglobin $B$ chain $[1,2]$. This leads to the production of abnormal hemoglobin chains within the red blood cell, which causes rigidity and sickling of the cell, leading to vascular occlusion and ischemia in multiple organs $[3$, 4]. The normal human hemoglobin molecule is a heterotetramer composed of four hemoglobin chains (two $\alpha$ and two $\beta$ ) and the normal adult hemoglobin is Hemoglobin AA [3]. The abnormal genes occur as a result of glutamic acid-to-valine substitution at the sixth base position in the $\beta$ hemoglobin gene on chromosome 11 [3]. Sickle cell anemia results from the inheritance of two sickle $\beta$ hemoglobin genes as HbSS [4].

Sickle cell anemia is particularly common among people whose ancestors come from sub-Saharan Africa, India, Saudi Arabia, and Mediterranean countries. Each year about 300,000 infants are born with major hemoglobin disorders - including more than 200,000 cases of sickle-cell anemia in Africa $[5,6]$. In Nigeria, by far the most populous country in the sub-region, $24 \%$ of the population are the carriers of the mutant gene $(\mathrm{HbAS})$ and the prevalence of sickle-cell anemia (HbSS) is about $2 \%$ [5, 7-9].

The resultant changes in the red blood cells causes chronic intermittent vasoocclusive events resulting in tissue ischemia; chronic hemolytic anemia resulting in varying degrees of anemia; and multiple organ damage from microinfarcts that can affect any organ in the body, including the bones, lungs, liver, kidneys, brain, eyes, heart, skin, and joints [2]. Episodes of crisis also occur and these include hemolytic crisis, aplastic crisis, acute sequestration crisis, and vaso-occlusive crisis [4].

There are documented established markers (indices) of disease severity in patients with SCA in the literature (Item 1) and they determine the course of the disease. These markers include both clinical and laboratory parameters [10, 11]. Identification of these markers of disease severity among adult SCA patients in steady state affords us the opportunity to know the course of the disease in these patients over the past years as well as to predict the likely course of the disease in the years to come. This would enable physicians to tailor management plans for the patients and also aid prompt intervention as the need arises, thereby preventing or reducing the complications that otherwise would have resulted. This would reduce the overall morbidity and mortality associated with SCA.

Presently, there is paucity of data in Nigeria on this topic. This study determined the pattern and the prevalence of the markers of disease severity in adult SCA patients in steady state in Ile-Ife, Nigeria, which now provides the much needed information for 
holistic management of these patients as well as scientific data for further research on this topic.

\section{Materials and Methods}

\subsection{Selection of study subjects}

This was a descriptive study that was carried out at the Hematology Clinic of a federal tertiary teaching hospital in lle-Ife, Osun state in the South Western geopolitical zone of Nigeria between June 2014 and April 2015. The inclusion criteria for this study consisted of patients $\geq 18$ years of age with SCA [Hemoglobin SS (HbSS) genotype], who must be in steady state and have given written informed consent to be recruited.

The following categories of patients were excluded from the study; patients less than 18 years of age, patients with other hemoglobinopathies such as $\mathrm{HbSC}, \mathrm{HbCC}, \mathrm{HbS} B$ thalassemia etc., patients in sickle cell crisis and patients who were pregnant. A total of 50 study subjects (patients) were recruited for the study. Selection of patients for the study was done by consecutive selection of 50 consenting SCA patients. Ethical approval was obtained from the Ethics and Research Committee of the institution.

\subsection{Evaluation of study subjects}

The patients were interviewed to elicit important relevant history and to ensure that they fulfill the set inclusion criteria for the study. A structured questionnaire was designed for the study which was used to collect demographic and relevant clinical information. The following information was obtained from the patients' case files (hospital records): frequency of crisis, last episode of crisis, nature of crisis, complications, previous hospitalizations, total units of blood transfusion ever received, steady state hemoglobin level, co-morbidities, drug history, family history of hemoglobinopathies and relevant social history.

The objective of the patient evaluation performed in this study was to identify the presence of the well-documented and established markers of disease severity in SCA patients. It was impossible to assess for all these markers in this study, thus some were selected. A physical examination was conducted on the study subjects including the measurement of anthropometric parameters (height and weight to calculate body mass index). Blood samples were collected to ascertain the hemoglobin genotype of the study subjects as well as for full blood count and serum bilirubin. 
Hepatic ultrasonographic evaluation was also performed for all the study subjects in order to assess for hepatomegaly which is one of the markers of disease severity and this was done in the ultrasound room of the Radiology Department of the institution. The hepatic ultrasound scan was done by the same Consultant Radiologist in order to avoid inter-observer variations and differences. A Mindray Real-Time Ultrasound machine model DC-7 was used. The liver span was taken as the liver length measured at the level of the mid-clavicular line along the long axis of the right lobe of the liver. In adults, hepatomegaly is defined as the long axis of the liver, longer than $155 \mathrm{~mm}$ and this cut-off was used in this study.

\subsection{Data analysis}

The data obtained was analyzed using the Statistical Package for the Social Sciences (SPSS) version 17.0 computer software package (SPSS Chicago Inc. IL U.S.A). Descriptive statistics used included frequency tables, percentages, means, and standard deviations.

\subsection{Study definitions}

Sickle cell anemia: Persons with Hemoglobin genotype SS (HbSS).

Normal individuals: Persons with Hemoglobin genotype AA (HbAA).

Steady state: A patient with SCA is said to be in steady state when there is no recent drop in the hemoglobin level and there is absence of infection, pain, acute complicating factors or acute clinical symptoms or crisis for at least three months established by a careful history and complete physical examination [12].

Sickle cell crisis: Crisis in patients with SCA refers to the episodes of acute illness attributable to the sickling phenomenon in which there is a sudden exacerbation of symptoms and signs of patients who had hitherto been in stable condition. This could be in the form of Pain or vaso-occlusive crisis, aplastic crisis, acute sequestration crisis, or hemolytic crisis [12]

\section{Results}

The study group (HbSS patients) comprised of 21 (42\%) males and 29 (58\%) females. The ages ranged from 18 to 45 years with a mean $( \pm S D)$ of $27.6 \pm 7.607$.

The BMl of the patients ranged from 15.10 to $26.50 \mathrm{~kg} / \mathrm{m}^{2}$ with a mean $( \pm S D)$ of $19.36 \pm 2.185$. The mean BMI for the patients was within the normal range. Twenty-four 
$(48 \%)$ of the patients were underweight, one (2\%) was overweight, and none was obese. Amongst the underweight patients, none fulfilled the criteria for failure to thrive (Table 1).

TABLE 1: The established markers (indices) of disease severity in sickle cell anemia [10, 11].

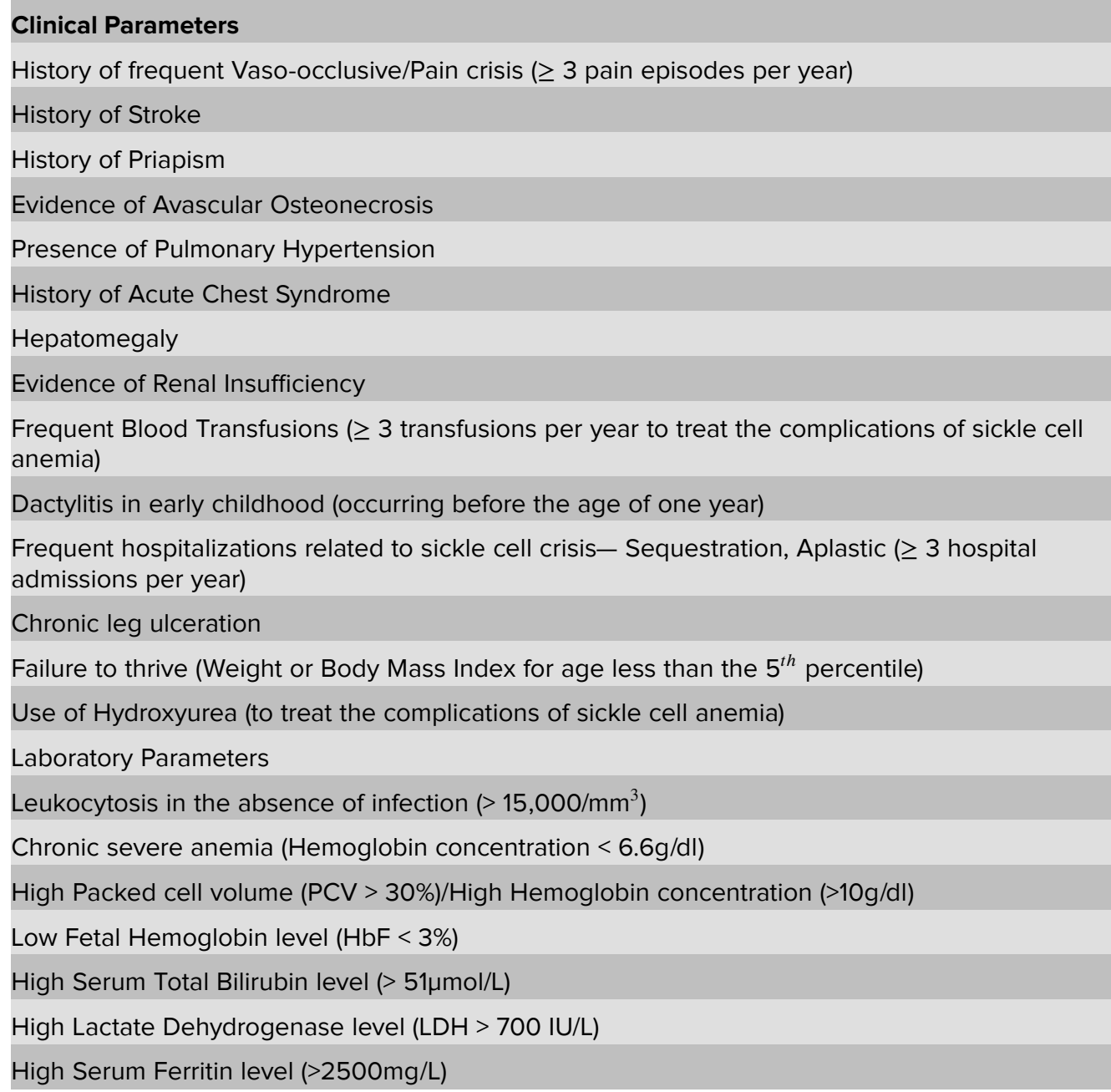

The mean $( \pm S D)$ age at first diagnosis of SCA in the patients was $6.46 \pm 4.827$ with a range of 3 months - 19 years. All of them had had one form of sickle cell crisis or the other in the past as shown in Table 2. All the patients had had vaso-occlusive crisis (VOC) in the past. Nineteen (38\%) patients experienced one episode of VOC per year while $15(30 \%)$ and $13(26 \%)$ experienced two and three episodes per year, respectively. Only 25 (50\%) of the patients had had hemolytic crisis in the past. Out of these 25 patients, $20(80 \%)$ and $3(12 \%)$ had one and two episodes per year, respectively. Only one patient (2\%) had hepatic sequestration crises in the past and only two (4\%) had ever had a splenic sequestration crisis in the past. None had aplastic crisis. Forty (80 \%) of the patients had had blood transfusion in the past. The units of blood received by the patients ranged from 1 to 30 units with a mean $( \pm S D)$ of $4.69 \pm 5.445$. One patient had 
had exchange blood transfusions done four times on account of complications of SCA; mainly repeated episodes of priapism. Six (12\%) patients had had $\geq 3$ units of blood transfused per year to treat the complications of SCA.

Thirteen (26\%) of the patients had dactylitis within the first year life. A 19-year old male patient (2\%) had two past episodes of left ischemic stroke. Two (4\%) patients had history of acute chest syndrome while four (8\%) had had priapism in the past. Four (8\%) patients had a past history of avascular necrosis of the femur, six (12\%) had chronic leg ulcer, two (4\%) had septic arthritis, and six (12\%) had a past history of chronic osteomyelitis (Table 2).

TABLE 2: History of sickle cell crisis and complications

\begin{tabular}{|c|c|c|}
\hline & Sickle Cell Crisis & \\
\hline \multirow[t]{2}{*}{ CRISIS } & PRESENT & ABSENT \\
\hline & NUMBER/(\%) & NUMBER/(\%) \\
\hline VASO-OCCLUSIVE & $50(100)$ & $0(0)$ \\
\hline HEMOLYTIC & $25(50)$ & $25(50)$ \\
\hline APLASTIC & $0(0)$ & $50(100)$ \\
\hline \multicolumn{3}{|l|}{ SEQUESTRATION } \\
\hline HEPATIC & $1(2)$ & $49(98)$ \\
\hline \multirow[t]{2}{*}{ SPLENIC } & $2(4)$ & $48(96)$ \\
\hline & Complications & \\
\hline \multirow[t]{2}{*}{ COMPLICATION } & PRESENT & ABSENT \\
\hline & NUMBER/(\%) & NUMBER/(\%) \\
\hline DACTYLITIS & $13(26)$ & $37(74)$ \\
\hline STROKE & $1(2)$ & $49(98)$ \\
\hline ACS & $2(4)$ & $48(96)$ \\
\hline PRIAPISM & $4(8)$ & $46(92)$ \\
\hline AVN & $4(8)$ & $46(92)$ \\
\hline SEPTIC ARTHRITIS & $2(4)$ & $48(96)$ \\
\hline CHRONIC LEG ULCER & $6(12)$ & $44(88)$ \\
\hline CHRONIC OSTEOMYELITIS & $6(12)$ & $44(88)$ \\
\hline
\end{tabular}

The full blood count and serum bilirubin results of the patients were as shown in Table 3. The range of the steady state hemoglobin concentration $(\mathrm{g} / \mathrm{dl})$ of the patients from their hospital records was $6.3-11.3 \mathrm{~g} / \mathrm{dl}$ with a mean $( \pm \mathrm{SD})$ of $8.52 \pm 1.114$. The range of the newly analyzed hemoglobin concentration of the patients was $5-12 \mathrm{~g} / \mathrm{dl}$ with a mean $( \pm S D)$ of $8.52 \pm 1.329$. Thirteen $(26 \%)$ of the patients had a serum total bilirubin value greater than $51 \mu \mathrm{mol} / \mathrm{L}$. 
The ultrasonographic liver span measurement of the patients ranged from 12.30 to $25.57 \mathrm{~cm}$ with a mean $( \pm \mathrm{SD})$ of $16.56 \pm 2.357$. The patients had a significantly long liver span (see Figure 1). Thirty-two (64\%) of the patients had a liver span longer than 15.5 $\mathrm{cm}$.

TABLE 3: Hematologic and biochemical investigation results.

Parameters
SS Hb. Conc. (g/dl)
SS PCV (\%)
Hb. Conc. (g/dl)
PCV $(\%)$
WBC $\left(/ \mathrm{mm}^{3}\right)$
PLT $\left(x 10^{3} / \mathrm{mm}^{3}\right)$
B1 $(\mu \mathrm{mol} / \mathrm{l})$
B2 $(\mu \mathrm{mol} / \mathrm{l})$

\begin{tabular}{|c|}
\hline Reference Values \\
\hline $5-9$ \\
\hline $15-27$ \\
\hline $11.5-17.5$ \\
\hline $36-52$ \\
\hline $3000-9000$ \\
\hline $100-300$ \\
$<20$ \\
$<5$ \\
\hline
\end{tabular}
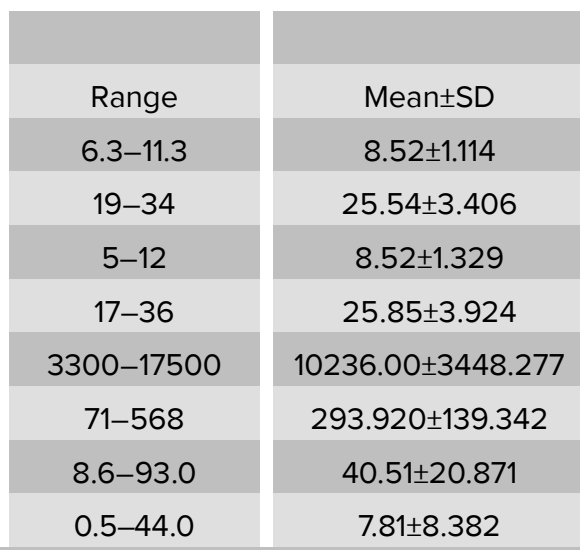

Note: SS Hb. Conc. = Steady State Hemoglobin Concentration; SS PCV = Steady State Packed Cell Volume; WBC = White Cell Count; PLT = Platelet Count; B1=Total Bilirubin; B2 = Conjugated Bilirubin; and NA = Not Applicable.

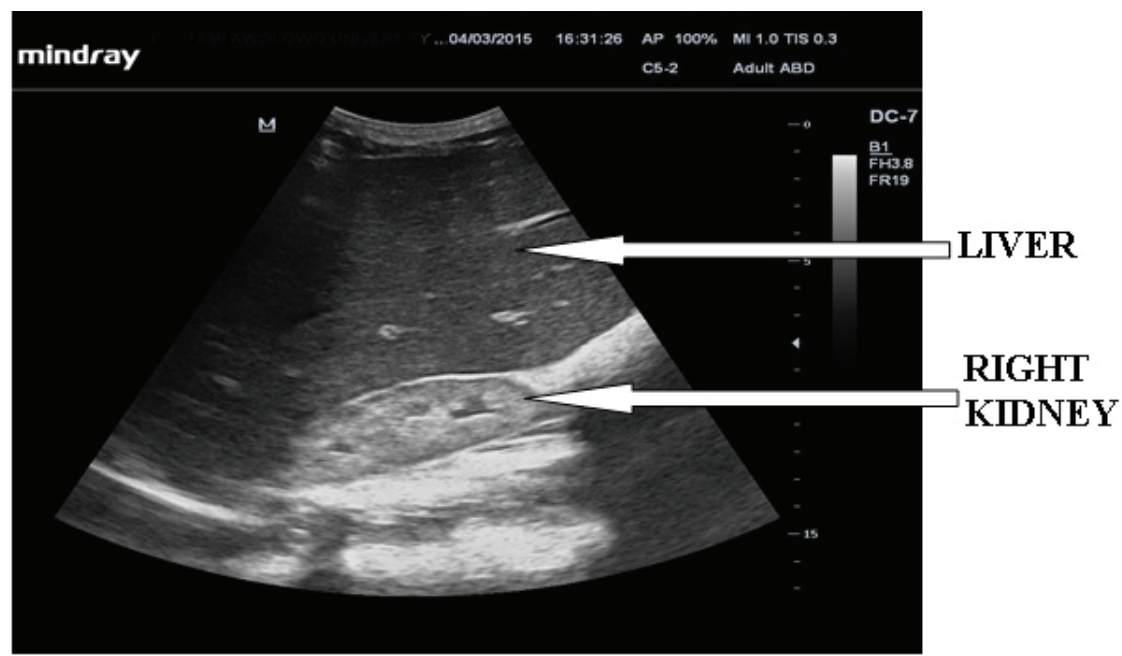

Figure 1: Sonogram showing massive hepatomegaly in a patient with sickle cell anemia (SCA). The lower lobe of the liver extends well below the lower pole of right kidney and the liver measures $22.3 \mathrm{~cm}$ in span exceeding the normal limit of $15.5 \mathrm{~cm}$.

Table 4 shows the markers of disease severity identified in the patients with SCA. Hepatomegaly (64\%), frequent episodes of vaso-occlusive crisis, that is, $\geq 3$ episodes per year (30\%), and dactylitis in infanthood (26\%) were the most common clinical parameters identified in these patients in that order, while a high serum total bilirubin of $>51 \mu \mathrm{mol} / \mathrm{L}(26 \%)$ was the most common laboratory parameter seen in these patients. 
Table 5 shows the total number of markers of SCA disease severity identified in the patients. Four (8\%) of the patients had no identified marker of disease severity while $43(86 \%)$ patients had between 1 and 4 identified markers of disease severity. Two (4\%) patients had five identified markers of disease severity and only one patient (2\%) had up to seven identified markers of disease severity. As shown in Table 6, more patients had clinical parameters than laboratory parameters; 43 (86\%) patients versus 23 (46\%) patients.

TABLE 4: Frequency of the indices of disease severity identified in the sickle cell anemia patients.

Clinical Parameters
History of frequent Vaso-occlusive/Pain crisis ( $\geq 3$ pain episodes per year)
History of Stroke
History of Priapism
Evidence of Avascular Osteonecrosis
History of Acute Chest Syndrome
Hepatomegaly
Evidence of Renal Insufficiency
Dactylitis in Early Childhood (occurring before the age of one year)
Chronic Leg Ulceration
Use of Hydroxyurea (to treat the complications of sickle cell anemia)
Frequent Blood Transfusions ( $\geq 3$ transfusions per year to treat the
complications of sickle cell anemia)
Laboratory Parameters
Leukocytosis in the absence of infection ( $>15,000 / \mathrm{mm}^{3}$ )
Chronic severe anemia (Hemoglobin concentration $<6.6 \mathrm{~g} / \mathrm{dl}$ )
High Serum Total Bilirubin level ( $>51 \mu m o l / L$ )
High Packed cell volume (PCV $>30 \%$ )/High Hemoglobin concentration (>10g/dl)

\begin{tabular}{|c|}
\hline $\begin{array}{c}\text { Number of } \\
\text { Patients (\%) }\end{array}$ \\
\hline $15(30)$ \\
$1(2)$ \\
\hline $4(8)$ \\
$44(8)$ \\
\hline $2(4)$ \\
\hline $32(64)$ \\
\hline $1(2)$ \\
\hline $13(26)$ \\
\hline $6(12)$ \\
\hline $1(2)$ \\
\hline $6(12)$ \\
\hline Number of \\
Patients (\%) \\
\hline $5(10)$ \\
\hline $2(4)$ \\
\hline $13(26)$ \\
\hline $5(10)$ \\
\hline
\end{tabular}

\section{Discussion}

Xandra et al. [13] defined the concept of severity as "the rate and extent of reversible and irreversible damage to organs brought on by the sickle cell disease process, resulting in impairment requiring medical intervention." Several attempts have been made till date by researchers to develop a universally accepted system for assessing disease severity in SCA patients and these include the Cooperative Study of Sickle Cell Disease (CSSCD) and the Bayesian Network Modeling (developed by Boston Medical Centre) [10].

Presently, there is no consensus scoring system for assessing the severity of disease in patients with SCA but a large number of indices have been used by researchers as 
TABLE 5: Total number of the indices of disease severity identified in the sickle cell anemia patients.

\begin{tabular}{l|c|c|c|c|c|}
$\begin{array}{l}\text { Clinical } \\
\text { Parameters }\end{array}$ & \multicolumn{2}{|l|}{ Laboratory Parameters } & \multicolumn{2}{|c|}{ Total Number of Parameters } \\
\hline Number & $\begin{array}{l}\text { Number of } \\
\text { Patients (\%) }\end{array}$ & Number & $\begin{array}{l}\text { Number of } \\
\text { Patients (\%) }\end{array}$ & Number & $\begin{array}{c}\text { Number of } \\
\text { Patients (\%) }\end{array}$ \\
\hline 0 & $7(14)$ & 0 & $27(54)$ & 0 & $4(8)$ \\
\hline 1 & $18(36)$ & 1 & $21(42)$ & 1 & $13(26)$ \\
\hline 2 & $13(26)$ & 2 & $2(4)$ & 2 & $16(32)$ \\
\hline 3 & $8(16)$ & TOTAL & $50(100)$ & 3 & $8(16)$ \\
\hline 4 & $3(6)$ & & & 4 & $6(12)$ \\
\hline 5 & $0(0)$ & & & 5 & $2(4)$ \\
\hline 6 & $1(2)$ & & & 6 & $0(0)$ \\
\hline TOTAL & $\mathbf{5 0 ( 1 0 0 )}$ & & & 7 & $1(2)$ \\
\hline
\end{tabular}

markers of disease severity in SCA, and these markers include clinical and laboratory parameters (Table 1) $[10,11]$. The presence of any of these markers in a patient with SCA connotes severe disease, and the severity of the disease increases with an increasing number of these markers present in an individual patient.

A high serum total bilirubin $(>51 \mu \mathrm{mol} / \mathrm{L})$ was the most common laboratory parameter observed in this study with a prevalence of $26 \%$. Elevated serum bilirubin levels, predominantly the unconjugated fraction, are universal in sickle cell patients even in steady state due to chronic hemolysis but a persistently high total bilirubin suggests chronic significant hemolysis in these patients signifying a severe disease course and there is a need to follow them up very closely.

Hepatomegaly (64\%) was the most common clinical parameter identified in this study. Frequent episodes of vaso-occlusive crisis ( $\geq 3$ episodes per year) and Dactylitis (occurring before the age of one year) were the other common clinical parameters identified in this study. Hepatomegaly is a common finding in SCA, and it is largely due to the extramedullary hematopoiesis in response to the chronic anemia in this condition $[3,4]$. Hepatomegaly can also be due to transfusional hemosiderosis and chronic viral hepatitis $[14,15]$. However, in Nigeria, which is a malaria endemic area, frequent episodes of malaria is also a major cause of the hepatomegaly seen in these patients [15]. In this study, the most common indication for hospital admission in the SCA patients apart from a sickle cell crisis was malaria; this could have contributed to the development of the hepatomegaly seen in these patients.

Olaniyi et al. found a prevalence of hepatomegaly of $62.2 \%$ among SCA patients in Ibadan, Nigeria [15]. Balci et al. found a prevalence of $72.6 \%$ among SCA patients in Turkey [16], and Papadaki et al. found a prevalence of $70.5 \%$ among sickle cell disease 
patients in Greece [17]. In this study, hepatic ultrasonographic evaluation of the patients revealed hepatomegaly with a prevalence of $64 \%$ (32 patients).

Persistent hepatomegaly is one of the established markers of disease severity in SCA patients [10, 11]. Olatunji et al. in Ilorin, Nigeria, also established that persistent hepatomegaly is an index of disease severity in patients with SCA [18]. Persistent hepatomegaly in patients with SCA implies that such patients have the tendency to run a more severe clinical course than those without and there is a need to pay more attention to them [18].

\subsection{Limitations of the study}

The findings from this study should be considered in line with some limitations that include absence of long-term patient follow-up in order to reassess these markers of disease severity for the long-term effect on the course of the disease. Also, this study selectively investigated some of the established markers of disease severity due to limited resources, thus the pattern of the other markers in these patients is not known. Future research should be geared towards developing a consensus scoring system for assessing disease severity in patients with SCA.

\section{Conclusion}

Hepatomegaly, frequent episodes of vaso-occlusive crisis, dactylitis in infanthood, and a high total bilirubin were the most common markers of disease severity identified in this study. A significantly larger number of patients had the clinical parameters compared to the laboratory parameters. Previous research had shown that the presence of any of these markers in an SCA patient connotes severe disease and the severity of the disease increases with increasing number of these markers present in an individual patient. Patients with more markers of disease severity have the tendency to run a more severe clinical course than those without or less markers and there is a need to pay more attention to these patients by following them up more closely.

Therefore, efforts should be stepped-up to maintain SCA patients in steady state as much as possible as this would prevent or limit complications or additional severity markers from arising, which could occur as a result of frequent crisis. Such efforts would reduce the overall morbidity and mortality associated with SCA. 


\section{Acknowledgement}

The authors would like to thank the members of the staff of Hematology and Radiology departments of Obafemi Awolowo University Teaching Hospitals Complex, lle-lfe, Nigeria, for their support towards making this research a success.

\section{Funding}

The authors bore the entire cost of the research and did not receive any financial support from any organization.

\section{Conflict of Interest}

The authors declared no conflicts of interest.

\section{References}

[1] Bender, M. A. and Hobbs, W. (2012). Sickle cell disease. GeneReviews ${ }^{T M}$. NCBI Bookshelf. Retrieved from: http://www.ncbi.nlm.nih.gov/pubmed/20301551 (accessed on May 17, 2012).

[2] Maakaron, J. E. and Besa, E. C. (2013). Sickle cell anemia. Medscape Reference. Retrieved from: http://www.emedicine.medscape.com/article/205926 (accessed on January 28, 2013).

[3] Beutler, E., Lichtman, M. A., and Coller, B. S. (eds.). (2001). Sickle cell disease, in William Hematology (sixth edition), pp. 581-589. McGraw-Hill.

[4] Hoffbrand, A. V., Catovsky, D., and Tuddenham, E. G. (eds.). (2005). Sickle cell disease, in Postgraduate Hematology (fifth edition), pp. 104-118. Blackwell.

[5] World Health Organization. (April 24, 2006). 59 ${ }^{\text {th }}$ World Health Assembly, Provisional Agenda Item 11.4, pp. 1-5. Geneva: WHO.

[6] Anie, K. A., Egunjobi, F. E., and Akinyanju, O. O. (2010). Psychosocial impact of sickle cell disorder: perspectives from a Nigerian setting. Globalization and Health, vol. 6, pp. 1-6.

[7] Durosinmi, M. A., Odebiyi, A. I., Akinola, N. O., et al. (1997). Acceptability of prenatal diagnosis of sickle cell anemia by a sample of the Nigerian population. African Journal of Medicine and Medical Sciences, vol. 26, pp. 55-58. 
[8] Halim, N. K., Famodu, A. A., and Wemambu, S. N. (eds.). (2001). Sickle cell disease, in Textbook of Clinical Hematology and Immunology (second edition), pp. 24-28. Ambik.

[9] Animasahun, B. A. and Temiye, E. O. (2011). The influence of socio-economic status on the hemoglobin level and anthropometry of sickle cell anemia patients in steady state at the Lagos University Teaching Hospital. Nigerian Journal of Clinical Practice, vol. 14, pp. 422-427.

[10] Sebastiani, P., Nolan, V. G., Baldwin, C. T., et al. (2007). A network model to predict the risk of death in sickle cell disease. Blood, vol. 110, pp. 2727-2735.

[11] Steinberg, M. H. (2005). Predicting clinical severity in sickle cell anemia. British Journal of Hematology, vol. 129, pp. 465-481.

[12] Bookchin, R. M. and Lew, V. L. (1996). Pathophysiology of sickle cell anemia. Hematology/Oncology Clinics of North America, vol. 10, pp. 124-1253.

[13] Xandra, W., Johanna, H., Harriet, H., et al. (2010). Development and validation of a pediatric severity index for sickle cell patients. American Journal of Hematology, vol. 85 , pp. 746-751.

[14] Banerjee, S., Owen, C., and Chopra, S. (2001). Sickle cell hepatopathy. Hepatology, vol. 33, pp. 1021-1028.

[15] Olaniyi, J. A. and Abjah, U. M. (2007). Frequency of hepatomegaly and splenomegaly in Nigerian patients with sickle cell disease. WAJM, vol. 26, pp. 274-277.

[16] Balci, A., Karazincir, S., Sangun, O., et al. (2008). Prevalence of abdominal ultrasonographic abnormalities in patients with sickle cell disease. Diagnostic and Interventional Radiology, vol. 14, pp. 133-137.

[17] Papadaki, M. G., Kattamis, A. C., and Papadaki, I. G. (2003). Abdominal ultrasonographic findings in patients with sickle-cell anemia and thalassaemia intermedia. Pediatric Radiology, vol. 33, pp. 515-521.

[18] Olatunji, P. O. and Falusi, A. G. (1994). Persistent hepatomegaly: an index of severity in sickle cell anemia. East African Medical Journal, vol. 71, pp. 742-744. 